Correspondence Maria A. Pando mpando@fmed.uba.ar

\section{Human immunodeficiency virus and tuberculosis in Argentina: prevalence, genotypes and risk factors}

\author{
Maria A. Pando, ${ }^{1}$ Cristina De Salvo, ${ }^{2}$ Christian T. Bautista, ${ }^{3}$ \\ Lindsay Eyzaguirre, ${ }^{4}$ Gladys Carrion, ${ }^{5}$ Miguel Feola, ${ }^{6}$ Isabel Lado, ${ }^{7}$ \\ Marta Hoffman, ${ }^{8}$ Mirna M. Biglione, ${ }^{1,9}$ Jean K. Carr, ${ }^{4}$ Silvia M. Montano, ${ }^{5}$
} José L. Sanchez, ${ }^{10,11}$ Mercedes Weissenbacher ${ }^{1,9}$ and Maria M. Avila ${ }^{1,9}$

${ }^{1}$ Centro Nacional de Referencia para el SIDA, Departamento de Microbiología, Parasitología e Inmunología, Facultad de Medicina, Universidad de Buenos Aires, Paraguay 2155, Piso 11 , C1121ABG, Buenos Aires, Argentina

${ }^{2}$ Division Neumotisiologia, Hospital General de Agudos Dr Enrique Tornu, Donato Alvarez 3002, 1406 Buenos Aires, Argentina

${ }^{3}$ US Military HIV Research Program at the Walter Reed Army Institute of Research, 1 Taft Court, Suite 250, Rockville, MD 20850, USA

${ }^{4}$ Department of Epidemiology, Institute of Human Virology, University of Maryland Biotechnology Institute, 725 W. Lombard Street, Baltimore, MD 21201, USA

${ }^{5}$ US Naval Medical Research Center Detachment (NMRCD), Unit 3800, APO-AA 34031-3800 Lima, Peru

${ }^{6}$ Tisioneumonologia, Hospital Gral. de Agudos Carlos C. Durand, Av. Díaz Vélez 5044, 1405, Buenos Aires, Argentina

${ }^{7}$ Servicio de Medicina Preventiva, Hospital Gral. Bernardino Rivadavia, Gral. Las Heras 2670, 1425, Buenos Aires, Argentina

${ }^{8}$ Laboratory, Microbiology Unit, Hospital General de Agudos Dr. Enrique Tornu, Donato Alvarez 3002, 1406, Buenos Aires, Argentina

${ }^{9}$ CONICET, Argentina

${ }^{10}$ Department of Defense Global Emerging Infections Surveillance and Response System (DoDGEIS), Walter Reed Army Institute of Research, 2900 Linden Lane, Suite 103, Silver Spring, MD 20910, USA

${ }^{11}$ Henry M. Jackson Foundation for the Advancement of Military Medicine, Inc., Rockville, MD 20852, USA

The objective of this study was to determine the prevalence and genetic variability of human immunodeficiency virus type 1 (HIV-1) and other sexually transmitted infections (STIs) among 205 patients with clinical diagnosis of tuberculosis (TB) in Buenos Aires in 2001. Infections with hepatitis B virus (HBV), HIV-1, hepatitis C virus (HCV), Treponema pallidum and human T-cell lymphotropic virus types I/II were diagnosed in 37/187 (19.8\%), 35/205 (17.1\%), 22/187 $(11.8 \%), 13 / 187(7.0 \%)$ and 4/181 (2.2\%) patients, respectively. Almost one in three participants (33.1\%) presented at least one infection in addition to TB. Multiresistance to TB drugs (isoniazid plus rifampicin) was detected in the isolates recovered from three patients. Injecting drug use was detected as the main risk factor for HIV, HBV and HCV infections. Of ten patients who died, eight were infected with HIV. HIV genetic characterization showed the presence of two different subtypes. Env subtype $F$ was found in 13/24 samples (54.2\%) and subtype B in $11 / 24$ samples $(45.8 \%)$ by heteroduplex mobility assay. Sequencing of the protease/RT region was performed in ten samples: three were characterized as subtype $B$ and seven as B/F recombinants by bootscanning analysis. Phylogenetic analysis of four full-length 
Received 3 July 2007

Accepted 10 October 2007 sequences showed that three were the circulating recombinant form CRF12_BF. The results of this study suggest an urgent need to detect HIV infection in high-risk groups to prevent future HIV transmission as well as morbidity and mortality associated with TB by providing highly active antiretroviral therapy (HAART) and/or TB treatment. Collaboration between TB and HIV programmes seems to be the best approach to decrease the incidence of these diseases, especially in high-prevalence HIV settings.

\section{INTRODUCTION}

Tuberculosis (TB) is the second most common infectious disease causing death worldwide after human immunodeficiency virus/acquired immunodeficiency syndrome (HIV/AIDS). The incidence of TB varies widely by region, with the highest incidence (356 per 100000 of the population) and mortality (81 per 100000$)$ in Africa and the lowest in the Americas (incidence: 41 per 100000; mortality: 5.9 per 100000 ) (Frieden et al., 2003; WHO, 2006).

Since 1980, much of the increase in the incidence of TB has been attributable to the impact of HIV/AIDS. Globally, an estimated $13 \%$ of adults with newly diagnosed TB in 2004 were also co-infected with HIV, but there was great variation among regions, from $34 \%$ in the African region to $1.4 \%$ in the Western Pacific region (Dye, 2006; WHO, 2006).

HIV is the highest single risk factor for progression to active TB disease in adults (Frieden et al., 2003). TB may occur relatively early in the course of HIV infection: the immunosuppression it induces modifies the clinical presentation of $\mathrm{TB}$, and $\mathrm{TB}$ influences the prognosis of HIV infection. In addition, anti-TB drugs interfere with antiretroviral drugs (Aaron et al., 2004).

The last epidemiological data for TB from Argentina in 2002 showed an incidence of 30.5 per 100000 inhabitants, with the highest rates in the north (Jujuy: 87.3; Salta: 72.7). In Buenos Aires city and surroundings, the incidence of $\mathrm{TB}$ is similar to that in the whole country. The mortality rate in Argentina is 2.6 per 100000 inhabitants, with the highest rate in the north (approx. 9 per 100000 inhabitants) (Liga Argentina Contra la Tuberculosis, 2003).

Previous studies (1988-1994) have reported an HIV prevalence of $3.1-21 \%$ in TB patients from Buenos Aires city (Musella et al., 1990; Putruele et al., 2006). However, no systematic research on HIV/TB co-infection is currently being undertaken. Therefore, the objectives of the present study were to estimate the prevalence and risk factors of HIV and other sexually transmitted infections (STIs), as well as the genetic variability among HIV strains in TB patients from Buenos Aires city.

\section{METHODS}

Study population and enrolment procedures. From July to December 2001, patients $\geqslant 18$ years old with a clinical diagnosis of TB who attended one of three public hospitals in Buenos Aires (Tornú, Durand and Rivadavia Hospitals) were invited to participate.

Participants were recruited through physicians, who explained the study objectives and procedures, and obtained written informed consent and clinical and epidemiological data in a confidential manner. Participants were invited to receive HIV testing and were offered pre-test and post-test counselling. All HIV-positive participants were subsequently referred for medical follow-up and a blood sample was collected for viral load, CD4 counting and HIV molecular genotyping (described below).

Hepatitis B virus (HBV), hepatitis C virus (HCV), Treponema pallidum and human T-cell lymphotropic virus type I/II (HTLV-I/II) infections were tested retrospectively in most of the samples after 1 year.

Blood sample collection and STI diagnosis. Anticoagulated blood $(10 \mathrm{ml})$ was collected in a sterile fashion. HIV was diagnosed by ELISA and agglutination (GENSCREEN Plus HIV Ag-Ab, Bio-Rad; Serodia HIV, Fujirebio). HBV infection was screened by ELISA (Wiener Laboratorios); reactivity to HBV surface antigen and/or anticore antibodies was considered as evidence of previous HBV infection. HCV infection was screened by ELISA (anti-HCV ELISA; Wiener Laboratorios). Screening for HTLV-I/II was performed by particle agglutination (Serodia HTLV-I; Fujirebio) and ELISA (Platelia HTLV-I New; Bio-Rad). Reactive samples were confirmed by Western blotting for HIV (Novapath HIV-1 Immunoblot; BioRad) or HTLV-I/II (HTLV Blot 2.4; Genelabs Diagnostics). Past T. pallidum infection was screened by VDRL test (Wiener Laboratorios).

HIV viral load was assessed using a Quantiplex HIV DNA (bDNA) assay (Chiron Diagnostics). The CD4 T-cell count was estimated using a Beckman Coulter EPICS XL flow cytometer.

Bacteriological studies. Sputum analysis was performed by direct examination of bacilli presence using Truant auramine-rhodamine staining. Bacterial culture was performed in parallel in LöwensteinJensen medium and Bactec $460 \mathrm{~TB}$ (following the manufacturer's recommendations). Bacterial sensitivity to isoniazid, streptomycin, rifampicin and ethambutol was performed for 102 isolates in parallel by the Canetti methodology in Löwenstein-Jensen medium and with Bactec 460 TB (following the manufacturer's recommendations).

Genotyping procedures. DNA extraction was performed with peripheral blood mononuclear cells (Qiagen). All 35 HIV-positive samples were subjected to PCR amplification of env and the protease/ reverse transcriptase (RT) regions, and four samples were subjected to almost full-length amplification. The env region was amplified and a heteroduplex mobility assay (HMA) was performed with secondround PCR products using nine reference standards, as described previously (Delwart et al., 1993). The protease/RT region was amplified using primers Pro5F/RT3474R in the first round and Pro3F/ProRT in the second round. Almost full-length sequences were determined using primers MSF12b/OFMR1 in the first round and F2NST/UNINEF 7 in the second round. The amplified products were sequenced with Big Dye terminators using an ABI 3100 automated 
sequencer (Applied Biosystems), assembled using Sequencer software (Genecodes) and examined in a multiple alignment with standard subtype references using CLUSTAL_X. Phylogenetic analyses were conducted by the neighbour-joining method with Kimura's twoparameter model of distance calculation and a bootstrap computed with 100 replicas using MEGA. Bootscanning and distance scanning were performed to determine the presence of recombination using Simplot (Lole et al., 1999).

Resistance profile. An antiretroviral drug resistance profile was performed considering mutations that have been associated with reduced susceptibility to protease and RT inhibitors, as reported by the International AIDS Society-USA (Stanford University HIV Drug Resistance Database).

Statistical analysis. Fisher's exact test or a $\chi^{2}$ test was utilized to compare proportions. Student's $t$-test or a Mann-Whitney U-test was used to compare continuous variables. Association of risk factors with HIV, HBV, HCV or T. pallidum infection were expressed as odds ratios (ORs) with $95 \%$ confidence intervals (95\% CI). ORs were adjusted for age and education in multiple logistic regression analyses. Risk factors with a value of $P<0.25$ in univariate analysis were selected for inclusion in stepwise forward multivariate logistic regression analyses with threshold values of $P=0.10$ for entry into and $P=0.05$ for removal from the model. All reported $P$ values were two-sided. Statistical analyses were conducted using Stata version 8.0.

\section{RESULTS AND DISCUSSION}

\section{Study population}

A total of 205 patients with clinical diagnosis of TB infection were enrolled, $65.9 \%$ of which were men. The mean age of participants was $34.8 \pm 14.1$ years. Sixty-two per cent of the participants were Argentinean; the rest were mainly from Peru (16.7\%) and Bolivia (15.8\%). Almost all of the participants lived in Buenos Aires city (43.1\%) and surrounding areas $(52.9 \%)$. A high educational level (approximately equivalent to high school) was reported by $59 \%$ of the participants, with women showing a significantly higher educational level $(70$ vs $53.3 \%$, $P=0.025) ; 80.5 \%$ of the participants were employees.

Irregular use of condoms (defined as 'occasional or no use at all') was reported by $58.6 \%$, whilst $6.4 \%$ reported experiencing condom tears. Previous STIs were declared by $20.6 \%$, with gonorrhoea being the most frequent. A history of transfusion was reported by $11.1 \%$. Tattoos were reported by $19.4 \%$, and were more frequent in men than in women ( 24.8 vs $8.8 \%, P=0.008)$. Ten per cent had been in prison, which was also more common in men (15.3 vs $1.5 \%, P=0.001)$. Approximately $4 \%$ of men defined themselves as homosexual. Illicit drug use was declared by $27.5 \%$ of men and $2.1 \%$ of women $(P<0.0001)$, and $9.4 \%$ were intravenous drug users (IDUs), also reported more frequently among men ( 12.7 vs $2.9 \%, P=0.023)$. Twelve per cent reported having had sex with an IDU partner and $12.4 \%$ reported having an HIV-positive partner. In men, $6.7 \%$ reported that they had exchanged sex for money, drugs or food occasionally during their lifetime. With regard to sexual attitudes, $16.3 \%$ of men and $5.8 \%$ of women reported having had more than one partner over the last 6 months $(P=0.024)$.

Previous BCG vaccination was reported by $75 \%$ of the study population. Eighty per cent were inpatients at the hospitals. Of the 205 patients, $20.7 \%$ were under TB treatment and in all of these $\mathrm{TB}$ disease was clinically confirmed by bacteriology or culture assays.

\section{Prevalences}

Infection with HBV, HIV, HCV, T. pallidum and HTLV-I/ II was diagnosed in $37 / 187$ (19.8\%), 35/205 (17.1\%), 22/ $187(11.8 \%), 13 / 187(7.0 \%)$ and $4 / 181(2.2 \%)$ participants, respectively (Table 1 ). HIV and HCV prevalence was found to be significantly higher among men, showing a risk of 2.5 and 10.7, respectively. Among the HTLV-positive cases, three were HTLV-I and one was HTLV-II. Table 2 shows the risk factors that were found to be statistically associated with higher prevalence of the infections analysed. Most HIV-positive cases (90\%) reported having previous HIV testing.

\section{Bacteriological results}

Sputum samples were analysed in 156 patients and 119 (76.3\%) were found to be positive. In 102 patients,

Table 1. Prevalence of HIV, HBV, HCV, HTLV-I/II and T. pallidum among 205 patients with TB in Buenos Aires, Argentina, 2001

\begin{tabular}{|c|c|c|c|c|c|c|c|}
\hline \multirow[t]{2}{*}{ Organism } & \multicolumn{2}{|c|}{ Total } & \multicolumn{2}{|c|}{ Women } & \multicolumn{2}{|c|}{ Men } & \multirow[t]{2}{*}{$P$ value } \\
\hline & $\begin{array}{c}\text { No. positive/ } \\
\text { no. studied }\end{array}$ & $\begin{array}{c}\text { \% Prevalence } \\
(95 \% \text { CI })\end{array}$ & $\begin{array}{c}\text { No. positive/ } \\
\text { no. studied }\end{array}$ & $\begin{array}{c}\text { \% Prevalence } \\
(95 \% \mathrm{CI})\end{array}$ & $\begin{array}{c}\text { No. positive/ } \\
\text { no. studied }\end{array}$ & $\begin{array}{c}\text { \% Prevalence } \\
(95 \% \mathrm{CI})\end{array}$ & \\
\hline $\mathrm{HBV}$ & $37 / 187$ & $19.8(14.3-26.2)$ & $9 / 64$ & $14.1(4.8-23.4)$ & $28 / 123$ & $22.8(14.9-30.6)$ & 0.109 \\
\hline HIV & $35 / 205$ & $17.1(12.2-23.9)$ & $6 / 70$ & $8.6(1.3-15.8)$ & $29 / 135$ & $21.5(14.2-28.8)$ & $0.020^{*}$ \\
\hline $\mathrm{HCV}$ & $22 / 187$ & $11.8(7.5-17.3)$ & $1 / 64$ & $1.6(0.04-8.4)$ & $21 / 123$ & $17.1(10.0-24.1)$ & $0.001^{\star}$ \\
\hline T. pallidum & $13 / 187$ & $7.0(3.8-11.6)$ & $3 / 64$ & $4.7(1.0-13.1)$ & $10 / 123$ & $8.1(2.9-13.4)$ & 0.548 \\
\hline HTLV-I/II & $4 / 181$ & $2.2(0.6-5.6)$ & $0 / 62$ & 0 & $4 / 119$ & $3.4(0.9-8.4)$ & 0.301 \\
\hline
\end{tabular}

${ }^{\star} \mathrm{HIV}$ and HCV infections were significantly more frequent in men than in women. 
Table 2. Prevalence of HIV, HBV, HCV and T. pallidum by potential risk factors among 205 patients with TB in Buenos Aires, Argentina, 2001

The total number of cases tested in each group varied because of missing data. Statistically significant variables $\left(P<0.05\right.$ by $\chi^{2}$ or Fisher's exact test $)$ are shown in bold.

\begin{tabular}{|c|c|c|c|c|c|c|c|c|}
\hline \multirow[t]{2}{*}{ Feature } & \multicolumn{2}{|r|}{ HIV } & \multicolumn{2}{|r|}{ HBV } & \multicolumn{2}{|r|}{$\mathrm{HCV}$} & \multicolumn{2}{|r|}{ T. pallidum } \\
\hline & $\%$ & No. positive/total & $\%$ & No. positive/total & $\%$ & No. positive/total & $\%$ & No. positive/total \\
\hline $18-24$ & 3.6 & $2 / 55$ & 6.0 & $3 / 50$ & 8.0 & $4 / 50$ & 2.0 & $1 / 50$ \\
\hline $25-29$ & 11.9 & $5 / 42$ & 13.9 & $5 / 36$ & 8.3 & $3 / 36$ & 5.6 & $2 / 36$ \\
\hline $30-44$ & 33.3 & $20 / 60$ & 33.3 & $18 / 54$ & 22.2 & $12 / 54$ & 7.4 & $4 / 54$ \\
\hline Other & 3.8 & $3 / 78$ & 18.9 & $14 / 74$ & 6.8 & $5 / 74$ & 5.4 & $4 / 74$ \\
\hline Argentinean & 25.6 & $32 / 125$ & 20.4 & $23 / 113$ & 15.0 & $17 / 113$ & 8.0 & $9 / 113$ \\
\hline \multicolumn{9}{|l|}{ Level of education } \\
\hline High school or higher & 10.7 & $13 / 121$ & 17.3 & $19 / 110$ & 8.2 & $9 / 110$ & 4.6 & $5 / 110$ \\
\hline Primary or less & 26.2 & $22 / 84$ & 23.4 & $18 / 77$ & 16.9 & $13 / 77$ & 10.4 & $8 / 77$ \\
\hline No & 12.4 & $22 / 178$ & 16.6 & $27 / 163$ & 6.1 & $10 / 163$ & 7.4 & $12 / 163$ \\
\hline Yes & 57.1 & $12 / 21$ & 50.0 & $9 / 18$ & 61.1 & $11 / 18$ & 5.6 & $1 / 18$ \\
\hline \multicolumn{9}{|l|}{ Tattoos } \\
\hline No & 13.0 & $21 / 162$ & 19.6 & $29 / 148$ & 7.4 & $11 / 148$ & 8.8 & $13 / 148$ \\
\hline Yes & 33.3 & $13 / 39$ & 20.0 & $7 / 35$ & 28.6 & $10 / 35$ & 0.0 & $0 / 35$ \\
\hline \multicolumn{9}{|l|}{ Use of injected drugs } \\
\hline No & 9.2 & $17 / 187$ & 15.3 & $26 / 170$ & 5.3 & $9 / 170$ & 6.5 & $11 / 170$ \\
\hline Yes & 94.7 & $18 / 19$ & 73.3 & $11 / 15$ & 86.7 & $13 / 15$ & 13.3 & $2 / 15$ \\
\hline \multicolumn{9}{|l|}{ Sexual partner use drugs } \\
\hline No & 8.8 & $14 / 159$ & 13.8 & $20 / 145$ & 6.2 & $9 / 145$ & 7.6 & $11 / 145$ \\
\hline Yes & 81.8 & $18 / 22$ & 60.0 & $12 / 20$ & 65.0 & $13 / 20$ & 10.0 & $2 / 20$ \\
\hline Yes & 34.1 & $14 / 41$ & 36.1 & $13 / 36$ & 13.9 & $5 / 36$ & 16.7 & $6 / 36$ \\
\hline \multicolumn{9}{|l|}{ Exchanged sex for goods } \\
\hline No & 15.4 & $30 / 195$ & 18.3 & $33 / 180$ & 11.1 & $20 / 180$ & 6.7 & $12 / 180$ \\
\hline Yes & 55.6 & $5 / 9$ & 66.7 & $4 / 6$ & 33.3 & $2 / 6$ & 16.7 & $1 / 6$ \\
\hline \multicolumn{9}{|l|}{ Use of illegal drugs } \\
\hline No & 10.0 & $18 / 180$ & 16.8 & $28 / 167$ & 7.8 & $13 / 167$ & 7.2 & $12 / 167$ \\
\hline Yes & 70.8 & $17 / 24$ & 47.4 & $9 / 19$ & 47.4 & $9 / 19$ & 5.3 & $1 / 19$ \\
\hline \multicolumn{9}{|l|}{ Condom breaking } \\
\hline No & 15.2 & $28 / 191$ & 18.9 & $33 / 175$ & 11.4 & $20 / 175$ & 7.4 & $13 / 175$ \\
\hline Yes & 46.2 & $6 / 13$ & 36.4 & $4 / 11$ & 18.2 & $2 / 11$ & 0.0 & $0 / 11$ \\
\hline \multicolumn{9}{|c|}{$\begin{array}{l}\text { Anal sex with condom in the last } \\
6 \text { months }\end{array}$} \\
\hline No & 58.3 & $7 / 12$ & 54.6 & $6 / 11$ & 63.6 & $7 / 11$ & 9.1 & $1 / 11$ \\
\hline Yes & 13.6 & $18 / 132$ & 16.9 & $20 / 118$ & 10.2 & $12 / 118$ & 5.1 & $6 / 118$ \\
\hline
\end{tabular}

Mycobacterium tuberculosis was isolated and an antibiogram was performed. Ninety-one isolates $(89.2 \%)$ were sensitive to all drugs and 10 presented the following resistance patterns: four were resistant to isoniazid, three to streptomycin and three were multiresistant (isoniazid plus rifampicin). 




Fig. 1. Distribution of co-infections among 181 patients with TB in Buenos Aires, Argentina, 2001. Others indicates other coinfections between HIV, HBV, HCV and T. pallidum.

\section{Co-infection}

Co-infection was studied in 181 participants $(88.3 \%)$ for whom full serological data were available. Almost one in three $(33.1 \%, n=60)$ presented at least one infection in addition to TB. Of these patients, 36 (19.9\%), ten (5.5\%), ten $(5.5 \%)$ and four $(2.2 \%)$ were diagnosed with two, three, four or five infections, respectively. The three most common co-infections were $\mathrm{TB} / \mathrm{HIV} / \mathrm{HBV} / \mathrm{HCV}$ (4.4\%), $\mathrm{TB} / \mathrm{HIV} / \mathrm{HBV}(2.2 \%)$ and $\mathrm{TB} / \mathrm{HIV} / \mathrm{HCV}$ (1.7\%). The distribution of co-infections is shown in Fig. 1. A significant association between HIV and HBV ( $P$ $<0.001)$, HIV and HCV $(P<0.001)$, HBV and HCV $(P$ $<0.001)$, HBV and HTLV-I/II $(P=0.025)$ and HCV and HTLV-I/II $(P=0.006)$ was observed.

\section{Risk factor analyses}

Table 3 shows the multiple logistic regression analyses of risk factors associated with HIV, HBV, $\mathrm{HCV}$ and $T$. pallidum infection. The significant risk factors for HIV infection were: age 25-44, Argentinean nationality, primary or lower level of education, unemployment, history of imprisonment, presence of tattoos, injected drug use, an IDU partner, an HIV-infected partner, a history of STI, sexual contact with men, exchange of sex for goods, illegal drug use and a history of condom tears. For HBV infection, risk factors were older age (30-44 years), unemployment, a history of imprisonment, injected drug use, an IDU partner, an HIV-infected partner, a history of STI,

Table 3. Multiple logistic regression analysis of risk factors associated with HIV, HBV, HCV and T. pallidum infection among 205 patients with TB in Buenos Aires, Argentina, 2001

AOR, odds ratio adjusted for gender, age and level of education. Categories in parentheses indicate the reference category for odds calculation. Statistically significant variables are shown in bold. NA, Not applicable.

\begin{tabular}{|c|c|c|c|c|c|c|c|c|}
\hline \multirow[t]{2}{*}{ Risk factor } & \multicolumn{2}{|c|}{ HIV } & \multicolumn{2}{|c|}{ HBV } & \multicolumn{2}{|c|}{$\mathrm{HCV}$} & \multicolumn{2}{|c|}{ T. pallidum } \\
\hline & AOR & $95 \%$ CI & AOR & $95 \%$ CI & AOR & $95 \%$ CI & AOR & $95 \%$ CI \\
\hline \multicolumn{9}{|l|}{ Age group } \\
\hline $25-29$ ( <25 years $)$ & 7.6 & $2.2-26.2$ & 2.7 & $0.7-11.0$ & 1.3 & $0.7-2.3$ & 3.2 & $0.7-14.7$ \\
\hline $30-44$ ( $<25$ years $)$ & 23.2 & $4.2-128.5$ & 8.0 & $1.7-36.3$ & 2.7 & $0.7-10.6$ & 3.3 & $2.8-4.0$ \\
\hline$\geqslant 45(<25$ years $)$ & 8.2 & $0.58-116.1$ & 4.9 & $1.2-19.3$ & 0.5 & $0.02-13.7$ & 5.7 & $1.2-26.7$ \\
\hline Argentinean nationality (other) & 6.8 & $1.5-31.1$ & 0.85 & $0.47-1.5$ & 2.4 & $1.2-4.7$ & 0.9 & $0.1-7.3$ \\
\hline $\begin{array}{l}\text { Primary or lower level of education } \\
\text { (high school or higher) }\end{array}$ & 2.0 & $1.5-2.7$ & 1.0 & $0.44-2.3$ & 2.4 & $0.42-14.2$ & 1.5 & $0.4-5.5$ \\
\hline No employment (yes) & 5.7 & 4.6-7.1 & 3.3 & $2.6-4.1$ & 3.7 & $2.7-5.0$ & 0.6 & $0.2-2.3$ \\
\hline History of imprisonment (no) & 10.9 & $4.4-26.6$ & 5.9 & $2.1-16.7$ & 17.6 & $4.8-64.3$ & 0.8 & $0.3-2.4$ \\
\hline Presence of tattoos (no) & 3.3 & $1.3-8.0$ & 1.1 & $0.47-2.6$ & 3.2 & $1.5-7.0$ & NA & NA \\
\hline Use of injected drugs (no) & 177.0 & $11.3-2780.7$ & 16.2 & $2.0-132.4$ & 189.5 & $7.1-5072.4$ & 2.3 & $0.5-10.5$ \\
\hline \multicolumn{9}{|l|}{ Sexual partner using drugs (no) } \\
\hline Yes & 73.9 & $31.7-172.5$ & 12.5 & $4.2-37.1$ & 39.2 & 21.7-71.0 & 1.6 & $0.3-7.6$ \\
\hline Do not know & 3.0 & $1.1-8.2$ & 2.8 & $1.6-5.0$ & NA & $\mathrm{NA}$ & $\mathrm{NA}$ & $\mathrm{NA}$ \\
\hline \multicolumn{9}{|l|}{ Sexual partner HIV-positive (no) } \\
\hline Yes & 328.5 & $44.9-2405.4$ & 12.1 & $3.4-43.8$ & 46.9 & $11.3-194.6$ & 1.9 & $0.7-5.7$ \\
\hline Do not know & 18.3 & $6.1-55.0$ & 2.1 & $0.8-5.6$ & 4.6 & $0.9-22.3$ & 0.4 & $0.1-1.1$ \\
\hline Prior history of STI (no) & 3.2 & $1.7-5.9$ & 2.3 & $1.1-4.7$ & 1.4 & $0.9-2.2$ & 2.7 & $0.5-15.1$ \\
\hline Sexual contact with men (no) & 4.7 & $3.2-6.9$ & NA & NA & NA & NA & NA & $\mathrm{NA}$ \\
\hline Exchanged sex for money/goods (no) & 3.7 & $1.6-8.6$ & 7.6 & $3.6-16.0$ & 2.1 & $0.7-7.0$ & 1.9 & $1.3-2.7$ \\
\hline Use of illegal drugs (no) & 42.0 & $19.0-92.5$ & 5.5 & $3.9-7.7$ & 7.7 & $5.6-10.5$ & 0.9 & $0.6-1.6$ \\
\hline Condom breaking (no) & 9.0 & $5.4-15.0$ & 4.1 & $1.3-13.5$ & 4.1 & $0.8-20.9$ & NA & NA \\
\hline Anal sex without condom (with condom) & 5.9 & $0.5-68.3$ & 5.3 & $1.6-17.9$ & 14.4 & $2.8-74.4$ & 1.7 & $0.5-6.3$ \\
\hline
\end{tabular}


exchange of sex for goods, illegal drug use, condom tears and unprotected anal intercourse. In contrast, Argentinean nationality, unemployment, history of imprisonment, presence of tattoos, injected drug use, an IDU partner, an HIV-infected partner and use of illegal drugs were the main risk factors associated with HCV infection. For T. pallidum infection, only older age and exchange of sex for goods were associated risk factors. Among HTLV-I/II infected patients, two were IDUs who were also HIV-infected; one was from Peru and the other one had a history of transfusion.

When a stepwise forward multivariate logistic regression analysis was applied, only some variables remained associated with HIV, HBV and HCV: age (OR 1.1, $95 \%$ CI 1.0-1.1), unemployment (OR 15.5, $95 \%$ CI 2.8-83.0), having a sexual partner with HIV (OR 41.8, $95 \%$ CI 4.7370.6 ) and use of injected drugs (OR 132.2, $95 \%$ CI 8.32111.1) for HIV; age (OR 1.04, $95 \%$ CI 1.01-1.07), use of drugs in the sexual partner (OR 5.17, 95\% CI 1.38-19.33) and use of injected drugs (OR 6.65, 95\% CI 1.53-28.89) for HBV; and use of drugs in the sexual partner (OR 11.58, $95 \%$ CI 6.78-19.80), being male (OR 24.15, $95 \%$ CI $4.71-$ 123.95 ) and use of injected drugs (OR 62.92, $95 \%$ CI 1.652398.94) for HCV.

The univariate analysis to identify the association between illicit drug use and other variables showed that the presence of tattoos, a history of imprisonment, an IDU partner, an HIV-infected partner, a higher number of sexual partners and exchange of sex for goods were highly reported in patients who reported being drug users. Stratified analysis of the study population showed that, in non-IDUs, condom tears, having an IDU partner and having an HIV-infected partner were the main risk factors associated with HIV infection.

Retrospectively, the outcome of the patients was disclosed: 143 patients were cured, 25 left the treatment, eight were referred to another hospital, five continued treatment when the study was concluded, ten died and no information was available for the remaining 14 participants. Of the ten patients who died, nine had at least one of the diagnosed infections and eight were HIV-positive.

\section{Genotyping, resistance profile, CD4 count and viral load in HIV-positive patients}

An env HMA was completed in $24 \mathrm{HIV}$-positive samples. Env subtype $\mathrm{F}$ was found in 13 samples $(54.2 \%)$ and subtype B in 11 samples $(45.8 \%)$. Ten samples were sequenced in the protease/RT region: three samples were found to be subtype $B$ and seven were $B / F$ recombinants by bootscanning analysis (Fig. 2). Three Env subtype F samples were sequenced in the protease/RT region and were found to be $\mathrm{B} / \mathrm{F}$ recombinants. Phylogenetic analysis (neighbour-joining and bootscanning analysis) of the fulllength sequences of four protease/RT B/F samples showed that three were the circulating recombinant form CRF12_BF and the other was a unique recombinant form.
Of the ten HIV-positive samples analysed, primary antiretroviral resistance was detected in three: ARG3002 (I54V, V82A, L90M, T69N, F116Y, Q151M and M184V), ARG3011 (L100I and K103N) and ARG3015 (G48V, L90M, V118I, K103E and Y181C).

The median viral load for the HIV-positive patients was $5.2 \mathrm{log}$ viral RNA copies $\mathrm{ml}^{-1}$ (158489 copies $\mathrm{ml}^{-1}$ ) and the median number of $\mathrm{CD}^{+} \mathrm{T}$ cells was 84 cells $\mathrm{ml}^{-1}$.

The results of this epidemiological study provide a better understanding of the status of the HIV/TB epidemic in Argentina. This study clearly indicates that a high proportion $(17.1 \%)$ of patients with $\mathrm{TB}$ are also infected with HIV. The high viral loads and low CD4 counts registered, together with the absence of previous opportunistic infections, suggest that TB was probably the first AIDS-defining illness. In HIV-infected patients, TB most often results from reactivation of latent $\mathrm{TB}$ infection (Aaron et al., 2004; Frothingham et al., 2005).

Different risk factors were detected in this study, but the use of injected drugs was by far the main risk factor associated with HIV and hepatitis infection. The overwhelming majority of patients who used injected drugs were infected with HIV (18/19), HCV (13/15) and HBV (11/15). This is consistent with previously reported data from our group among injecting drug users in Buenos Aires (Weissenbacher et al., 2003).

$\mathrm{TB}$ is the main cause of hospitalization among HIVinfected injecting drug users at Muñíz Hospital (the national reference hospital for infectious diseases in Argentina). Two out of three HIV-positive IDU patients experience at least one TB episode following infection. Moreover, it was observed that among HIV-infected individuals, the chance of developing pulmonary or extra-pulmonary $\mathrm{TB}$ is twice as high in IDUs as it is in non-IDUs (Moscatello, 2003).

In those patients who do not use injected drugs, sexual risks (condom tears, or having an IDU or HIV-positive sexual partner) were the main risk factors associated with HIV infection. As previously reported for other risk groups in Buenos Aires, these variables related mainly to a low socioeconomic level, and included unemployment, exchange of sex for goods and history of imprisonment, and were also associated with hepatitis infection (Pando et al., 2003, 2004, 2006).

Multiresistant TB was detected at high prevalence in Argentina during the 1990s and was particularly associated with AIDS patients attending some hospitals in large urban centres such as the Muñiz Hospital (Palmero et al., 2006). In 1999, a countrywide survey depicted $1.8 \%$ multiresistant TB (WHO/IUATLD, 2004). In this study, only three patients who had already received $\mathrm{TB}$ treatment presented multiresistance (isoniazid plus rifampicin). These three patients declared very low or no treatment adherence and one was also HIV-positive. 


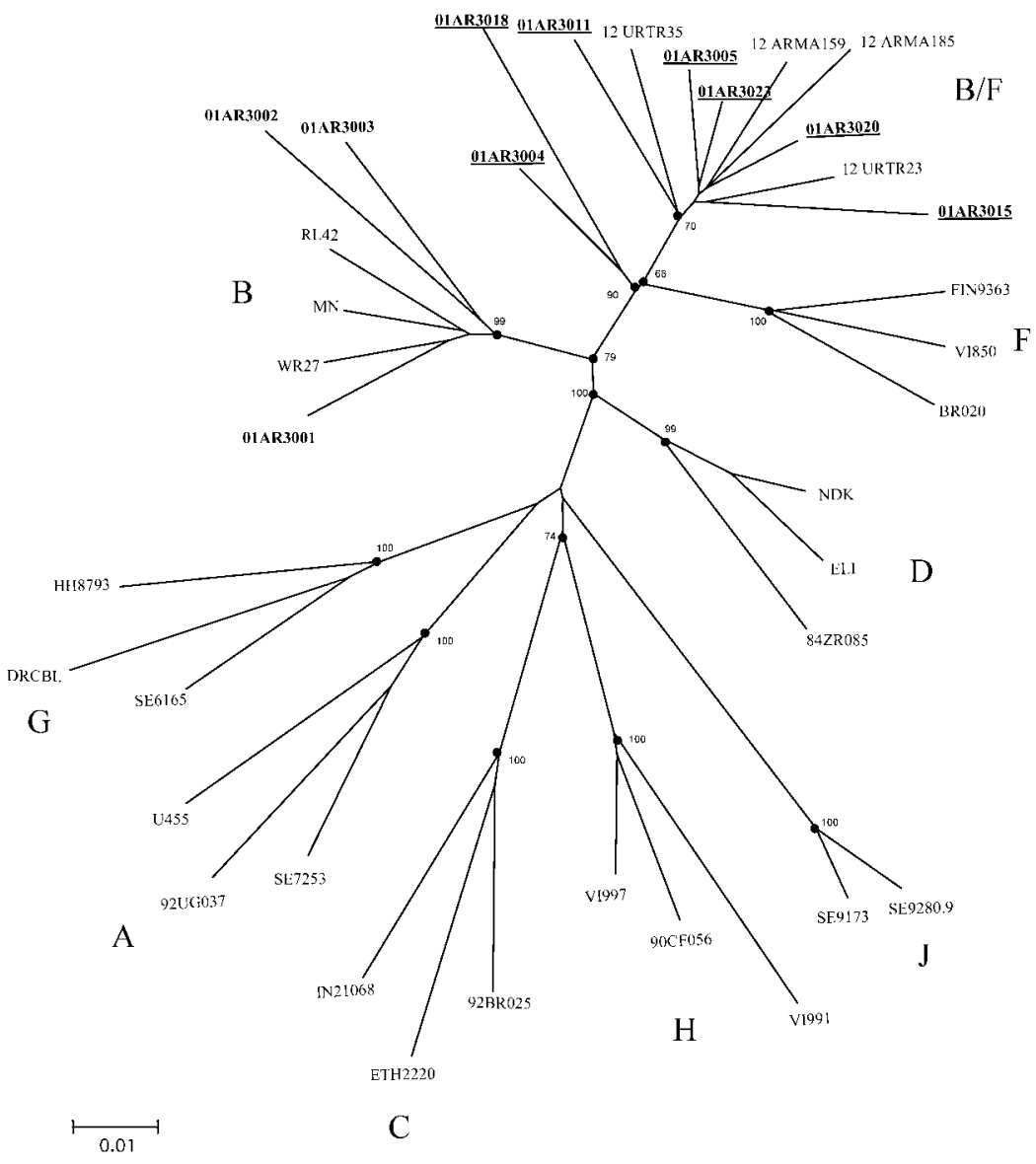

Fig. 2. Phylogenetic analysis of ten pol sequences from patients with TB infection from Buenos Aires, Argentina. A neighbourjoining phylogenetic tree analysis was performed with the Kimura two-parameter method of distance estimation using reference sequences. The bar shows the genetic distance corresponding to the length of the branches. Studied samples are in bold; intersubtype recombinants are underlined.

TB rates have declined in many countries. Therefore, most cases observed in these countries have been attributed to immigrants from high-incidence countries (CDC, 2006). A high proportion of patients recruited in this study were immigrants from the neighbouring countries of Peru and Bolivia. In both of these countries, TB incidence is much higher than in Argentina. Bolivia and Peru have a TB incidence range of $100-300$ per 100000 , whilst Argentina is in the range of 25-49 per 100000 (WHO, 2002). However, HIV prevalence was significantly lower in these patients than in Argentinean patients, suggesting that, in most foreign patients, TB was not related to HIV infection.

The results of genetic characterization showed the presence of two different subtypes, as was previously detected in heterosexual men and women (Ávila et al., 2002). HMA showed the co-existence of subtypes B and F (54.2 vs $45.8 \%$ ) and sequencing analysis showed that all of the Env subtype $\mathrm{F}$ samples sequenced in the protease/RT region were $\mathrm{B} / \mathrm{F}$ recombinants as previously noted (Ávila et al., 2002; Carr et al., 2001). The high prevalence of $\mathrm{B} / \mathrm{F}$ recombinants and CRF12_BF described in this group is in accordance with previous studies performed in IDUs (Espinosa et al., 2004).

In summary, there is a close relationship between HIV and $\mathrm{TB}$ infection in Argentina. This relationship has been confirmed subsequently around the world, and approximately $12 \%$ of HIV/AIDS-associated deaths worldwide are deemed to be due to TB complications (Reid et al., 2006). The results of this study indicate that there is a priority need to screen for HIV infection in this high-risk group of patients in order to prevent future HIV transmission as well as morbidity and mortality associated with TB by providing highly active antiretroviral therapy (HAART) and/or TB treatment. Increased and more effective collaboration between TB and HIV control and treatment programmes needs to be effected in order to be able to diminish morbidity/mortality in this setting.

\section{ACKNOWLEDGEMENTS}

We thank all the volunteers for participating and Moira Vignoles and Mariel Bibini for their assistance in HIV serology diagnosis and cytometry analysis. This study was supported by the US Military HIV Research Program at the Walter Reed Army Institute of Research, Rockville, MD, and by the US Naval Medical Research Command, Silver Spring, MD (Work unit no. 62787A 873 H B0002). The study was approved by institutional review boards and scientific ethical committees at the University of Buenos Aires and at the US Naval Medical Research Center in the USA. The opinions and assertions contained herein are private ones and do not reflect the official position of the Argentinean Ministry of Health, the Department of Defense, the US Department of the Navy or Army, or the Henry M. 
Jackson Foundation for the Advancement of Military Medicine, Inc. or any other organization listed.

\section{REFERENCES}

Aaron, L., Saadoun, D., Calatroni, I., Launay, O., Mémain, N., Vincent, V., Marchal, G., Dupont, B., Bouchaud, O. \& other authors (2004). Tuberculosis in HIV-infected patients: a comprehensive review. Clin Microbiol Infect 10, 388-398.

Ávila, M. M., Pando, M. A., Carrión, G., Martínez Peralta, L., Salomón, H., Gómez Carrillo, M., Sánchez, J., Maulen, S., Hierholzer, J. \& other authors (2002). Two epidemics in Argentina: different genetic subtypes associated with different risk groups. J Acquir Immune Defic Syndr 29, 422-426.

Carr, J. K., Ávila, M. M., Gómez Carrillo, M., Salomón, H., Hierholzer, J. Watanaveeradej, V., Pando, M. A., Negrete, M., Russell, K. L. \& other authors (2001). Diverse BF recombinants have spread widely since the introduction of HIV-1 into South America. AIDS 15, F41-F47.

CDC (2006). Trends in tuberculosis - United States, 2005. MMWR Morb Mortal Wkly Rep 55, 305-308.

Delwart, E. L., Shpaer, E. G., Louwagie, J., McCutchan, F. E., Grez, M., Rübsamen-Waigmann, H. \& Mullins, J. I. (1993). Genetic relationships determined by a DNA heteroduplex mobility assay: analysis of HIV-1 env genes. Science 262, 1257-1261.

Dye, C. (2006). Global epidemiology of tuberculosis. Lancet 367, 938-940.

Espinosa, A., Vignoles, M., Carrillo, M. G., Sheppart, H., Donovan, R., Peralta, L. M., Rossi, D., Radulich, G., Salomón, H. \& Weissenbacher, M. (2004). Intersubtype BF recombinants of HIV-1 in a population of injecting drug users in Argentina. J Acquir Immune Defic Syndr 36, 630-636.

Frieden, T. R., Sterling, T. R., Munsiff, S. S., Watt, C. J. \& Dye, C. (2003). Tuberculosis. Lancet 362, 887-899.

Frothingham, R., Stout, J. E. \& Hamilton, C. D. (2005). Current issues in global tuberculosis control. Int J Infect Dis 9, 297-311.

Liga Argentina Contra la Tuberculosis (2003). Situación de la Tuberculosis Republica Argentina, 2002. Revista Argentina del Tórax 64. Available at http://www.lalat.org.ar/revista/vol64/actualizacion.htm.

Lole, K. S., Bollinger, R. C., Paranjape, R. S., Gadkari, D., Kulkarni, S. S., Novak, N. G., Ingersoll, R., Sheppard, H. W. \& Ray, S. C. (1999). Full-length human immunodeficiency virus type 1 genomes from subtype C-infected seroconverters in India, with evidence of intersubtype recombination. $J$ Virol 73, 152-160.

Moscatello, G., Campello, P. \& Benetucci, J. A. (2003)..Bloodborne and sexually transmitted infections in drug users in a hospital in Buenos Aires, Argentina.Clin Infect Dis 37 (Suppl. 5), S343-347.
Musella, R. M., Castagnino, J. P., Weber, L., Boxaca, M. C., Weissenbacher, M. C., Abbate, E. H. \& González Montaner, L. J. (1990). Human immunodeficiency virus infection associated with tuberculosis. Medicina (B Aires) 50, 3-8 (in Spanish).

Palmero, D., Ritacco, V., Ambroggi, M., Poggi, S., Guemes Gurtabay, J., Alberti, F. \& Waisman, J. (2006). Multidrug-resistant tuberculosis in AIDS patients at the beginning of the millennium. Medicina (B Aires) 66, 399-404 (in Spanish).

Pando, M. A., Maulen, S., Weissenbacher, M., Marone, R., Duranti, R., Peralta, L. M., Salomón, H., Russell, K., Negrete, M. \& other authors (2003). High HIV-1 seroprevalence in men who have sex with men in Buenos Aires, Argentina: risk factors for infection. Int J Epidemiol 32, 735-740.

Pando, M. A., Biglione, M. M., Toscano, M. F., Rey, J., Russell, K. L., Negrete, M., Gianni, S., Martínez-Peralta, L., Salomón, H. \& other authors (2004). Human immunodeficiency virus type 1 and other viral co-infections among young heterosexual men and women in Argentina. Am J Trop Med Hyg 71, 153-159.

Pando, M. A., Berini, C., Bibini, M., Fernández, M., Reinaga, E., Maulen, S., Marone, R., Biglione, M., Sánchez, J. \& other authors (2006). Prevalence of HIV-1 and other sexually transmitted infections among female commercial sex workers in Argentina. Am J Trop Med Hyg 74, 233-238.

Putruele, A. M., Limongi, L. F., Legarreta, C. G., Martínez, P. R., Davidovich, A. \& Kempf, N. (2006). Evaluación diagnóstica y tratamiento en 457 casos de tuberculosis. Abstracts of the 11th International Internal Medicine Congress of the Hospital de Clínicas. Medicina (B Aires) 66 (Suppl. 1), 3 (in Spanish).

Reid, A., Scano, F., Getahun, H., Williams, B., Dye, C., Nunn, P., De Cock, K. M., Hankins, C., Miller, B. \& other authors (2006). Towards universal access to HIV prevention, treatment, care, and support: the role of tuberculosis/HIV collaboration. Lancet Infect Dis 6, 483-495.

Weissenbacher, M., Rossi, D., Radulich, G., Sosa-Estáni, S., Vila, M., Vivas, E., Avila, M. M., Cuchi, P., Rey, J. \& Peralta, L. M. (2003). High seroprevalence of bloodborne viruses among street recruited injection drug users from Buenos Aires, Argentina. Clin Infect Dis 37 (Suppl. 5), S348-S352.

WHO (2002). Global Tuberculosis Control: Surveillance, Planning, Financing. Available at http://www.who.int/tb/publications/global_ report/en/. Geneva: World Health Organization.

WHO (2006). Tuberculosis. Fact sheet no. 104. Revised March 2007. http://www.who.int/mediacentre/factsheets/fs104/en/print.html. Last access November 2006. Geneva: World Health Organization.

WHO/IUATLD (2004). Project on Anti-tuberculosis Drug Resistance Surveillance. Anti-tuberculosis Drug Resistance in the World. Report no. 3. WHO/TB 99.269. Geneva: World Health Organization. 